\title{
Nicotinic Acetylcholine Receptors in Sensory Cortex
}

\author{
Raju Metherate \\ Department of Neurobiology and Behavior, University of California, Irvine, Irvine, California 92697, USA
}

\begin{abstract}
Acetylcholine release in sensory neocortex contributes to higher-order sensory function, in part by activating nicotinic acetylcholine receptors ( $\mathrm{nAChRs).} \mathrm{Molecular} \mathrm{studies} \mathrm{have} \mathrm{revealed} \mathrm{a} \mathrm{bewildering} \mathrm{array} \mathrm{of} n A C h R$ subtypes and cellular actions; however, there is some consensus emerging about the major nAChR subtypes and their functions in sensory cortex. This review first describes the systems-level effects of activating nAChRs in visual, somatosensory, and auditory cortex, and then describes, as far as possible, the underlying cellular and synaptic mechanisms. A related goal is to examine if sensory cortex can be considered a model system for cortex in general, because the use of sensory stimuli to activate neural circuits physiologically is helpful for understanding mechanisms of systems-level function and plasticity. A final goal is to highlight the emerging role of nAChRs in developing sensory cortex, and the adverse impact of early nicotine exposure on subsequent sensory-cognitive function.
\end{abstract}

Nicotinic acetylcholine receptors (nAChRs) contribute to sensory-cognitive functions, as demonstrated in numerous behavioral studies (Warburton 1992; Turchi et al. 1995; Rezvani et al. 2002). The contribution likely involves nAChRs located within sensory systems, including sensory cortex, that mediate the cholinergic role in attention and other cognitive functions ${ }^{1}$ (Sarter et al. 2001). An understanding of the role of nAChRs in sensory cortex function requires integrating information on the different subtypes of nAChRs, how they respond to acetylcholine (ACh) or psychoactive drugs, where they are found (which areas and layers, on which cell types, and whether they are pre- or postsynaptic), and the consequences of their activation for the processing of sensory information in neural circuits. Although considerable information exists regarding the molecular biology, cellular physiology, and general distribution in the brain of nAChR subtypes (Jones et al. 1999; Dani 2001; Leonard and Bertrand 2001), complementary information on how nAChRs function within specific cortical circuits is needed to understand nicotinic functions in sensory cortex-or, for that matter, anywhere in the CNS (Alkondon and Albuquerque 2003; Clarke 2003; Metherate and Hsieh 2003).

The neuronal nAChR is a pentamer that can include a combination of $\alpha$ and $\beta$ subunits as a heteromeric receptor, or five $\alpha$ subunits as a homomeric receptor (Dani 2001; Leonard and Bertrand 2001). Although there are genes for a large number of subunits $(\alpha 2-10, \beta 2-4)$, most nAChRs in cortex are thought to exist as heteromers with $\alpha 4$ and $\beta 2$ subunits or as $\alpha 7$ homomers (note that this scenario is almost certainly an oversimplification). From a functional viewpoint, knowing the receptor composition is important because subunits contribute distinct functional characteristics, as shown by studying different subunit combinations in expression systems (Role and Berg 1996; Fenster et al. 1997). Notably, $\alpha 7$-containing receptors are known for rapid desensiti-

\footnotetext{
${ }^{1} \mathrm{ACh}$ activates two broad classes of receptors, namely, nicotinic and muscarinic receptors. Whereas this review focuses on nicotinic receptors, many studies have established the importance of muscarinic receptors in modulating sensory cortex function and plasticity (for reviews, see Weinberger and Bakin 1998; Edeline 1999; Rasmusson 2000; Metherate and Hsieh 2003).
}

E-MAIL rmethera@uci.edu; FAX (949) 824-2447.

Article and publication are at http://www.learnmem.org/cgi/doi/10.1101/ Im.69904. zation in the presence of agonist and high $\mathrm{Ca}^{2+}$ permeability ${ }^{2}$ (Zhang et al. 1994; Castro and Albuquerque 1995), whereas $\alpha 4 \beta 2$ containing receptors have higher affinity to nicotine and slower rates of densensitization (Fenster et al. 1997).

There is remarkably little information on how nAChRs are engaged within cortical circuits, in part because synaptic actions of ACh at cortical nAChRs are difficult to demonstrate and study (in contrast, e.g., to ACh at the neuromuscular junction or glutamate in the cortex). The reasons for this difficulty lie partly in the nature of the cholinergic innervation of neocortex. The major source of cortical ACh is the nucleus basalis in the basal forebrain, whose cholinergic neurons are intermixed with noncholinergic neurons (some of which also project cortically), and whose cortical projection is diffuse (Rye et al. 1984; Dykes 1997). Such features make the cholinergic projection difficult to stimulate selectively. Also, cholinergic actions in the cortex appear to involve tonic release via "volume transmission," whereby ACh is released far from its postsynaptic targets (Umbriaco et al. 1994; but see Turrini et al. 2001). Although it may seem odd to have a transmitter system that incorporates, for example, tonic volume transmission with postsynaptic receptors that desensitize very rapidly, overcoming experimental design problems to be able to study such features will be key to understanding the role of nAChRs in cortical circuits.

Given the obstacles to studying synaptic actions at nAChRs, it is not surprising that most functional information has been obtained using receptor agonists such as nicotine. Although agonist use is common in receptor studies, it takes on special significance for nAChRs because nicotine is the main psychoactive agent in tobacco. Nicotine from cigarette smoke affects sensory perception and cognitive processes, and the effects of its use on brain function have been studied extensively (Warburton 1992; Dani and Heinemann 1996). Thus, nicotinic agonists are useful not only for studying the properties of nAChRs, but also for un-

\footnotetext{
${ }^{2}$ Permeability to $\mathrm{Ca}^{2+}$ is an important feature of some nAChRs, for example, presynaptic receptors whose activation results in increased neurotransmitter release (Wonnacott 1997), and $\alpha 7$ receptors may be even more permeable to $\mathrm{Ca}^{2+}$ than NMDA receptors (Seguela et al. 1993). Also, nAChR-associated increases in intracellular $\mathrm{Ca}^{2+}$ levels can result from the activation of voltagedependent $\mathrm{Ca}^{2+}$ channels or release from intracellular stores (Zhang et al. 1994; Sharma and Vijayaraghavan 2003).
} 
derstanding how tobacco use-systemically administered nicotine-affects neuronal circuitry and function.

Finally, there is a growing awareness that nAChRs may have distinct functions at different stages of life. In particular, several recent studies have found distinct and possibly unique mechanisms at work during brain development (Role and Berg 1996; Broide and Leslie 1999), including the development of sensory cortex (Metherate and Hsieh 2003). Given these findings, it is not surprising that smoking by pregnant women can impact fetal brain development (a particularly tragic consequence of nicotine addiction is that many women do not quit smoking during pregnancy; Oncken and Kranzler 2003). The effects of prenatal nicotine exposure can be detected even years later in the children of smokers (Ernst et al. 2001; Fried and Watkinson 2001).

\section{Focus of This Review}

The goal of this review is to highlight the extent to which nAChRs regulate sensory information processing, and to promote an understanding of the underlying mechanisms. The review focuses on the cellular and system-level effects of activating nAChRs in sensory neocortex (visual, somatosensory, and auditory cortex). Molecular and behavioral studies are not emphasized, although the effects of nicotine at specific nAChR subtypes, and on sensory-cognitive function, are noted. A secondary goal is to examine the extent to which sensory cortex can be considered a model system for cortex in general. Sensory systems can serve as useful models because physiological activation of neural circuits is possible (using sensory stimuli), thus enabling studies that integrate information across levels from the molecular to psychophysics. To that end, the review notes relevant differences and similarities with nonsensory cortical regions, and directs the interested reader to the literature for further details. A final goal of the review is to highlight the emerging role of nAChRs in developing sensory cortex, and the impact of early nicotine exposure on subsequent sensory-cognitive function.

\section{Cortical nAChRs Regulate Responses to Sensory Stimuli}

A simple observation to begin with is that administering nicotine systemically in humans, or smoking tobacco ${ }^{3}$, alters physiological measures of sensory responsiveness that involve sensory cortex, for example, sensory-evoked neural responses recorded from the scalp. In smokers, smoking increased the amplitude of longlatency visual (flash)-evoked potentials, whereas abstinence from smoking for many hours reduced the evoked potential amplitude (Hall et al. 1973; Friedman and Meares 1980). Similarly, in the auditory system, smoking increased the amplitude and reduced the peak latency of middle latency (midbrain and forebrain) components of an auditory (click)-evoked potential relative to the response obtained following a period of abstinence, or relative to the response in nonsmokers (Kishimoto and Domino 1998; but see Friedman and Meares 1980). Earlier latency (brainstem) components of the auditory-evoked potential appeared unaffected by smoking or abstinence. Enhancement of visualevoked potentials was seen after smoking cigarettes containing $1.34 \mathrm{mg}$ of nicotine relative to cigarettes containing $0.14 \mathrm{mg}$ (considered a pharmacologically ineffective dose), implicating nicotine or its metabolites in the effect (Woodson et al. 1982).

\footnotetext{
${ }^{3}$ Smoking tobacco increases levels of nicotine in the blood and brain (Isaac and Rand 1972; Henningfield et al. 1993). Although nicotine is considered the main psychoactive ingredient in tobacco, note that nicotine metabolites exert effects on the brain, as do other components of tobacco smoke (e.g., carbon monoxide), and that some consequences of nicotine administration may be indirect, for example, resulting from changes in brain blood flow or nicotineinduced release of neuromodulators or hormones (Benowitz 1996; Crooks and Dwoskin 1997; Domino et al. 2000; Ernst et al. 2001; Oncken and Kranzler 2003).
}

In a more direct examination of nicotine's effects on auditory processing, systemic nicotine delivered to nonsmokers transdermally, via a nicotine "patch," did not affect a measure of peripheral auditory function (otoacoustic emissions in the cochlea), but did affect CNS responses to auditory stimuli (Harkrider and Champlin 2001a,b; Harkrider et al. 2001). The study was conducted on nonsmokers to avoid complications arising from the effects of chronic nicotine exposure, but consequently was limited to a low-dose patch because of unpleasant side effects (dizziness, nausea; the patch was designed to release $7 \mathrm{mg} / 24 \mathrm{~h}$ and remained in place for $4 \mathrm{~h}$ ). The patch produced modest changes (both increases and decreases) in latency and amplitude of specific evoked potential components associated with auditory nuclei throughout the auditory pathway, including increased amplitude and decreased latency of long-latency (forebrain) potentials.

Examining nicotine's effects in animals enables more precise localization of recorded signals. In awake restrained cats, systemic nicotine (25-100 $\mu \mathrm{g} / \mathrm{kg}$, i.p.) increased the peak amplitude of the click-evoked potential recorded from the surface of auditory cortex (Guha and Pradhan 1976). A lower dose (12.5 $\mu \mathrm{g} / \mathrm{kg}$ ) transiently reduced the evoked response. In the anesthetized rat, similar systemic doses of nicotine $(25-100 \mu \mathrm{g} / \mathrm{kg}$, i.p.) appeared not to affect the click-evoked potential recorded from the surface of auditory cortex (Bhargava et al. 1978). However, a more recent study found that a higher dose $(0.7 \mathrm{mg} / \mathrm{kg}$, s.c. $)$ enhanced the magnitude and reduced the latency of pure toneevoked field potentials recorded in layer 4 of rat auditory cortex (Liang and Metherate 2003). In rat visual cortex, nicotine (0.35 $\mathrm{mg} / \mathrm{kg}$, i.p.) reduced a longer-latency component (N41) of the flash-evoked epidural potential (Bringmann 1994).

These studies demonstrate that systemically administered nicotine affects sensory processing, and that changes may occur at multiple levels in each sensory pathway. This is consistent with known cholinergic anatomy; for example, nicotine's effects on distinct components of the auditory-evoked response is consistent with the widespread distribution of nAChRs in the auditory pathway (Morley and Happe 2000). Another important point to remember is that systemic nicotine likely activates cortically projecting neuromodulatory systems (e.g., the "reticular activating system" and nucleus basalis) that contribute to the modification of sensory-evoked cortical responses (Shute and Lewis 1967; Guha and Pradhan 1976; Lewandowski et al. 1993; Metherate and Ashe 1993; Azam et al. 2003). Obviously, changes in cortical responses could incorporate nicotinic actions at several subcortical levels.

The involvement of cortical nAChRs can be demonstrated by direct manipulation within the cortex. Iontophoretic application of the nAChR antagonist mecamylamine $(100 \mu \mathrm{M}$ pipette solution) in the middle layers of cat visual cortex reduced single unit responses to visual stimuli (moving bars; Parkinson et al. 1988). Similarly, in rat auditory cortex, microinjection of $10 \mu \mathrm{M}$ mecamylamine into the middle layers reduced tone-evoked potentials in layer 4 (Liang and Metherate 2003). Both studies implicate cortical nAChRs in the regulation of sensory responses. Importantly, because reduction of evoked responses occurred during delivery of antagonist alone (i.e., in the absence of exogenous nicotine), the findings also imply that tonic release of endogenous ACh acts at nAChRs to regulate sensory responses.

Complementary results have been obtained from rat somatosensory cortex, where deflection of a whisker evokes neural activity in a cortical area centered over the appropriate whisker representation ("barrel"). Nicotine $(100 \mu \mathrm{M})$ applied to the cortical surface increased the peak amplitude and area of the whisker representation, as assessed by intrinsic signal imaging (Penschuck et al. 2002). Control studies showed that the imaging 
technique preferentially samples activity in the upper and middle cortical layers, and the method of agonist application also preferentially affects the same layers. In another study, intracortical microdialysis of nicotine $(1 \mathrm{mM}$ delivered to the microdialysis probe; estimated $<10 \%$ concentration in adjacent tissue) enhanced the whisker-evoked field potential recorded in layer 4 adjacent to the microdialysis probe, but did not affect the intracortical response to electrical stimulation of nearby cortex (Oldford and Castro-Alamancos 2003). Taken together, these studies demonstrate that nAChRs located in the primary auditory, visual, and somatosensory cortices contribute to the enhancement of sensory responses. ${ }^{4}$

\section{Cellular Bases of Nicotinic Regulation of Sensory Cortex} Early in vivo studies of cholinergic drugs applied iontophoretically to single neurons in cat and rat sensory cortex noted infrequent increases in spontaneous activity with nicotine, and only moderate effectiveness of neuromuscular junction antagonists such as curare (Krnjevic and Phillis 1963; Stone 1972; Lamour et al. 1982). In general, these studies implied a far greater role for muscarinic receptors in mediating effects of ACh. The lack of prominence given to nicotinic actions may have resulted from unrecognized features of neuronal nAChRs such as rapid receptor desensitization, preferential location on interneurons and presynaptic terminals, and pharmacology unlike that of muscle nAChRs.

More recent anatomical studies reinforce the likelihood of nicotinic actions in sensory cortex, in particular providing evidence that nAChRs regulate thalamocortical transmission (Clarke 2003). Studies in rat brain show dense, high-affinity $\left[{ }^{3} \mathrm{H}\right]$ nicotine binding (hereafter referred to as nicotine binding) through much of the neocortex, including sensory cortex, mostly in cortical layers 3 and 4 (but also in layers 1 and 6), where thalamocortical inputs terminate (Clarke et al. 1984, 1985; London et al. 1985). (Notably, $\alpha$-bungarotoxin [ $\alpha$ BTX] binding sites are not in the middle layers but are deeper in layer 6 instead.) In cat visual cortex, similar dense nicotine binding is found in layers $3 / 4$, with a dramatic drop in density at borders of visual cortex (decreased density at the area $17 / 18$ border, and again at the area 18/19 border; Prusky et al. 1987; Parkinson et al. 1988). These authors tested the notion that nAChRs are associated with thalamocortical fibers by surgically undercutting the cortex or by making electrolytic lesions of the lateral geniculate nucleus (LGN). These manipulations reduced the dense layer 4 binding. In contrast, excitotoxic lesions of visual cortex, which destroyed neurons within the cortex, but not afferent fibers, did not significantly affect the layer 4 band. These data support the idea that nAChRs are found on afferent terminals, in particular those of thalamocortical projections. Note that the incomplete, although substantial, loss of cortical nicotine binding even after extensive thalamic lesions, along with apparently complete loss of binding after cortical undercut, indicates the existence of presynaptic nAChRs associated with other afferent systems.

In similar experiments in the rat, excitotoxic or electrolytic thalamic lesions centered on the ventrobasal thalamus (but extending beyond its borders) that reduced layer 4 nicotine binding in sensory-motor cortex did not affect labeled muscarinic receptors, whereas excitotoxic lesions of the cortex reduced muscarinic, but not nicotinic, labeling (Sahin et al. 1992). The authors

\footnotetext{
${ }^{4}$ Another form of sensory processing, "sensory gating," involves $\alpha 7$ nAChRmediated regulation of auditory processing in the hippocampus (Adler et al. 1998; Freedman et al. 2000). A sensory gating deficit has been observed in schizophrenics, and has been attributed to a genetic defect underlying impaired $\alpha 7$ nAChR function in hippocampal interneurons. Notably, this and other symptoms are transiently reversed by nicotine, a finding that may explain the very high rates ( $-90 \%)$ of smoking among schizophrenics.
}

concluded that nAChRs are located on thalamocortical terminals, whereas muscarinic receptors are located postsynaptically on cortical neurons. Subsequent studies have found similar results in rat auditory and visual systems (Lavine et al. 1997): excitotoxic thalamic lesions centered on the medial geniculate (MG) or LGN reduced nicotine binding in layer 4 of auditory cortex or visual cortex, respectively. Conversely, excitotoxic lesions of temporal/auditory cortex did not affect nicotine binding, despite loss of cortical neurons. Importantly, the authors note that subsequent to the earlier studies, it had been demonstrated that high-affinity nicotine-binding sites reflect nAChRs containing $\alpha 4$ and $\beta 2$ subunits (whereas low-affinity nicotine- or $\alpha$ BTX-binding sites are thought to reflect $\alpha 7$ receptors; Couturier et al. 1990; Seguela et al. 1993). Thus, a contribution to the nicotine-induced increase in sensory cortex responsiveness ("Cortical nAChRs Regulate Responses to Sensory Stimuli" section above) may depend on presynaptic, $\alpha 4 \beta 2$-containing nAChRs that regulate thalamocortical transmission.

The idea that presynaptic nAChRs regulate thalamocortical transmission must be tested in physiological experiments. Cellular and synaptic physiology in sensory cortex is examined mostly in brain slices from young rodents ${ }^{5}$, and this particular issue is best addressed using a thalamocortical slice preparation (Agmon and Connors 1991; Cruikshank et al. 2002). In the only direct test to date, $1 \mu \mathrm{M}$ bath-applied nicotine enhanced thalamicevoked glutamatergic responses, but did not affect intracortically evoked responses, in layer 4 of the somatosensory thalamocortical slice obtained from 2- to 3-week-old rats or mice (Gil et al. 1997). Curiously, the effect in rat slices was blocked by $0.1-0.5$ $\mu \mathrm{M}$ methyllycaconitine (MLA; reportedly selective for $\alpha 7$ nAChRs) or by $10 \mu \mathrm{M}$ mecamylamine (reportedly nonselective among nAChR subtypes); however, in mouse slices the effect was blocked by mecamylamine but not MLA. The authors concluded that the nicotine effect was due to $\alpha 7$ receptors in rats, and non$\alpha 7$ receptors in mice. These results imply an interesting species difference; however, it should be noted that the MLA dose used may block non- $\alpha 7$ receptors, and the mecamylamine dose may preferentially block non- $\alpha 7$ receptors (e.g., Raggenbass and Bertrand 2002). Also, the authors did not explicitly consider the rapid changes in nAChR expression that occur during the first three postnatal weeks in sensory cortex and thalamus (Fuchs 1989; Bina et al. 1995; Broide et al. 1995, 1996). These changes are detailed below ("nAChRs and Sensory Cortex Development"), and it remains a possibility that different nAChR subtypes regulate thalamocortical transmission at different ages (e.g., Fig. 1). Nonetheless, the results support the general hypothesis that presynaptic nAChRs regulate thalamocortical transmission in sensory cortex.

In vitro studies also have demonstrated the cellular basis of rapid excitation of postsynaptic neurons that is mediated by nAChRs, and it now appears that in sensory cortex, such actions are most prominent in interneurons (but see "Synaptic Responses and Other Evidence for Endogenous Activation of nAChRs" below). This may have contributed to the early findings of infrequent nicotine-mediated excitation in vivo, because it is difficult to record from interneurons in vivo. In the last decade, however, studies have been able to target sparse or small neurons in brain slices because of technical advances that enable whole-cell

\footnotetext{
${ }^{5}$ Note that the anatomical work cited above derives from adult rats and cats, whereas most slice work is done in 2- to 3-week-old rodents (it is widely known among slice physiologists, though rarely mentioned in print, that whole-cell recordings become considerably more difficult in animals older than $\sim 3 \mathrm{wk}$ ). Thus, physiological results from slices may unwittingly reflect processes that occur only during postnatal development; such changes in nAChR function have become more apparent recently (see "nAChRs and Sensory Cortex Development" below).
}

\section{Learning \& Memory}

www.learnmem.org 
A Postnatal Week 2

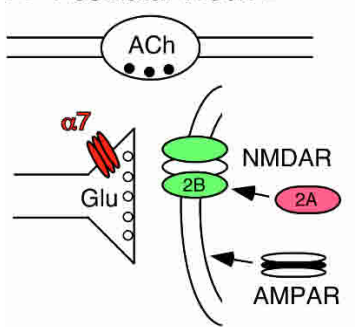

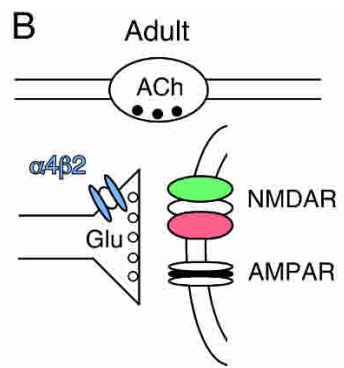

aptic label) across all layers. Because label was found mostly at axospinous synapses, which likely indicate synapses onto pyramidal neurons rather than (aspinous) interneurons, it is hard to integrate these data with the above physiological data showing excitation of interneurons, but not pyramidal neurons. It may be important that the physiological studies described above did not, for the most part, examine nicotinic regulation of glutamatergic transmission; further, the authors suggest that some $\alpha 7$ mediated functions are not easily detected physiologically (Levy and Aoki 2002).

Overall, the bulk of anatomical and physiological studies to date support two main functions of nAChRs in sensory cortex: presynaptic regulation of thalamocortical (glutamatergic) transmission and postsynaptic excitation of a subset of GABAergic interneurons.

\section{Related Findings in Nonsensory Cortex}

This and subsequent sections with the same subtitle compare actions of nAChRs in sensory to nonsensory cortex, with the emphasis on highlighting broad similarities and differences. Additionally, some relevant

(patch) recordings from visually identified neurons (Blanton et al. 1989; Dodt and Zieglgansberger 1990). The following studies all have exploited these newer techniques.

In visual cortex slices from $\sim 2$-week-old rats, ACh $(5 \mathrm{mM}$, micropressure ejection) strongly and rapidly depolarized lowthreshold spiking (LTS) interneurons in layer 5, an effect that was blocked by the nicotinic antagonist hexamethonium $(5 \mathrm{mM}$, micropressure ejection; Xiang et al. 1998). These GABAergic interneurons preferentially project to the upper cortical layers, and would be expected to inhibit pyramidal neurons within the same cortical "column" when excited. Interneurons in layer 1 have been studied in slices from the somatosensory cortex of 2- to 3-week-old rats (Christophe et al. 2002). Layer 1 has a particularly rich innervation of cholinergic axons and putative synapses (Mechawar et al. 2000). Micropressure-ejected nicotinic agonists excited nearly all layer 1 interneurons (97 of 101); the agonistinduced responses had fast and slow response components that showed pharmacological sensitivity consistent with $\alpha 7$ and non$\alpha 7$ receptors, respectively. (Some layer 1 interneurons excited by nicotine also are known to contain the peptides VIP and/or CCK, in addition to GABA, and receive synaptic inputs mediated by serotonin; Ferezou et al. 2002.) The authors then performed singlecell RT-PCR to show that the cells contained mRNA for $\alpha 4, \alpha 7$, and $\beta 2$ subunits, implying that each interneuron's mixed nAChR population included $\alpha 7$ homomers and $\alpha 4 \beta 2$ heteromers. Finally, they demonstrated that nicotinic agonist application to layer 1 resulted in IPSPs recorded in many layer $2 / 3$ interneurons, though never in layer $2 / 3$ pyramidal neurons, indicating that nicotinic excitation of layer 1 disinhibits deeper layers via inhibition of layer $2 / 3$ interneurons. Together, these studies indicate robust nicotinic excitation of several types of GABAergic interneuron.

These studies are somewhat at odds with experiments showing nicotinic synaptic transmission in pyramidal neurons in ferret visual cortex (Roerig et al. 1997; discussed below), and a recent ultrastructural study of somatosensory cortex in 1-week-old and adult rats (Levy and Aoki 2002). The latter study demonstrated antibody label for $\alpha 7$ nAChRs associated with $>70 \%$ of glutamate synapses (mostly postsynaptic, but also some presyn- findings from nonsensory cortex are mentioned even if comparison studies in sensory cortex have not yet been performed.

Several studies have examined nicotinic actions in prefrontal cortex, in part because of the putative role of nAChRs in cognitive/attentional processes mediated by prefrontal cortex (Granon et al. 1995). Studies analogous to those described above for sensory cortex make the case that nAChRs regulate thalamocortical afferents from the mediodorsal thalamic nucleus (MD) to prefrontal cortex (Vidal and Changeux 1989, 1993; Lavine et al. 1997; Gioanni et al. 1999). In anatomical experiments, excitotoxic MD lesions reduced nicotine binding preferentially in prefrontal cortex. In physiological experiments, nicotinic agonists facilitated the glutamatergic response to stimulation of MD (in vivo) or afferents within the cortical thalamorecipient layer (in vitro). In microdialysis experiments, nicotine increased cortical glutamate release in vivo. Both functional assays (electrophysiology and microdialysis) revealed pharmacological sensitivity that implicates $\alpha 4 \beta 2$ subunits. In a novel in vitro approach, nicotinic agonists were found to increase the frequency of spontaneous excitatory postsynaptic currents (EPSCs) in prefrontal neurons that receive thalamocortical inputs; this apparent presynaptic (and in fact, the authors conclude, given that tetrodotoxin blocks the effect, "preterminal") effect did not occur in slices from rats with thalamic lesions, nor in transgenic mice lacking $\beta 2$ subunits (Lambe et al. 2003). Together, these studies provide good evidence that $\alpha 4 \beta 2 \mathrm{nAChRs}$ regulate thalamocortical transmission in prefrontal cortex, as in mature sensory cortex.

Data from hippocampal neurons, in brain slices or in cell culture, also provide evidence for presynaptic actions of nAChRs, but with a different pharmacological profile. Nicotinic receptors have been shown to enhance glutamate release via increased $\mathrm{Ca}^{2+}$ influx into presynaptic terminals; however, the pharmacological data indicate $\alpha 7$-containing nAChRs (Gray et al. 1996). Enhanced glutamate release can be maintained in the presence of low concentrations of agonist (e.g., $0.5 \mu \mathrm{M}$ nicotine), presumably reflecting the involvement of nAChR-mediated $\mathrm{Ca}^{2+}$ influx, and, possibly, reduced receptor desensitization with low agonist concentrations (Shao and Yakel 2000). Following strong agonist 
stimulation, enhanced glutamate release can outlast the presence of agonist for minutes (Radcliffe and Dani 1998). Nicotinic increases in the frequency of spontaneous GABAergic currents also can depend on $\alpha 7$ receptors (Radcliffe et al. 1999; Alkondon and Albuquerque 2001), and recent data also have implicated $\alpha 3 \beta 4$ containing receptors in the control of glutamate release (Alkondon et al. 2003). Thus, the predominant pharmacology of presynaptic nAChR actions in hippocampus may differ from that of prefrontal or sensory neocortex.

Finally, as with sensory cortex, nAChR-mediated postsynaptic excitation in other cortical regions often occurs in interneurons. In brain slices from motor cortex, parietal association cortex, and hippocampus, nicotinic agonists exert negligible direct actions on pyramidal/principal neurons (however, see Ji et al. 2001) but strongly excite GABAergic and other local circuit neurons via non- $\alpha 7$ and, especially, $\alpha 7$ nAChRs; this action could, in turn, strongly inhibit pyramidal neurons (Jones and Yakel 1997; Frazier et al. 1998b, 2003; Porter et al. 1999; Alkondon et al. 2000; Ji and Dani 2000; Ji et al. 2001; Christophe et al. 2002).

\section{Synaptic Responses and Other Evidence for Endogenous Activation of $\mathrm{nAChRs}$}

Despite abundant evidence for functional nAChRs in cortex, remarkably few studies have reported direct evidence for nicotinic synaptic transmission. In particular, only one study to date has recorded synaptic currents mediated by nAChRs in sensory cortex. In visual cortex brain slices taken from ferrets over a wide age range ( 2 to 10 weeks old), both spontaneous and stimulus-evoked EPSCs occurred in pyramidal neurons found in layers 2-3 and 5-6, and in interneurons (both spiny and aspiny) found in layer 4 (Roerig et al. 1997). The EPSCs were blocked by $100 \mu \mathrm{M}$ dihydo$\beta$-erythroidine $(\mathrm{DH} \beta \mathrm{E})$, but not by $200 \mathrm{nM} \alpha \mathrm{BTX}$, implicating non- $\alpha 7$ receptors. Two findings stand out, especially in light of the studies reviewed above. First, both spontaneous and evoked EPSCs were of relatively small amplitude (e.g., 5-60 pA); however, the authors note that seemingly weak synaptic currents may carry additional weight given the $\mathrm{Ca}^{2+}$ permeability of nAChRs (although high $\mathrm{Ca}^{2+}$ permeability is more prominently a feature of $\alpha 7$ nAChRs). Second, nicotinic EPSCs were observed commonly in pyramidal neurons, whereas agonist-mediated excitation of pyramidal neurons is rare in other studies. Given the number of differences among the studies (e.g., species), future experiments must be designed carefully to resolve the seeming discrepancy.

Indirect evidence for activation of nAChRs by endogenous transmitter in sensory cortex also exists, and is consistent with the hypothesized role of nAChRs to regulate thalamocortical afferents. The evidence has been described in previous sections, and includes sensory-evoked responses being reduced by the antagonist mecamylamine delivered alone (Parkinson et al. 1988; Liang and Metherate 2003), or being enhanced by the delivery of anticholinesterase (or nicotine; Oldford and Castro-Alamancos 2003). Obviously, the success of this approach requires ongoing release of ACh in cortex, even in anesthetized animals, and indeed, this has been demonstrated by direct measurements (Celesia and Jasper 1966; Phillis 1968; Rasmusson et al. 1994). (In a related vein, it should be noted that choline, a precursor to ACh and product of ACh hydrolysis, is a selective agonist at $\alpha 7$ nAChRs; Alkondon et al. 1997.) The tonic release of cortical ACh in virtually all conditions (and even in brain slices; Metherate and Ashe 1995)-albeit at greater or lesser levels in different states of arousal-is an oft-forgotten but important feature that must be kept in mind when designing and interpreting cholinergic studies.

\section{Related Findings in Nonsensory Cortex}

Nicotinic EPSCs also have been observed in slices from hippocampus (Alkondon et al. 1998; Frazier et al. 1998a; Hefft et al. 1999) and frontal cortex (Chu et al. 2000). Synaptic currents were observed in both interneurons and pyramidal neurons (again, in contrast to agonist studies), were of small amplitude $(-2 \%-10 \%$ of the total synaptic response), show reversal potentials near 0 $\mathrm{mV}$, and often show strong dependence on $\alpha 7$ receptors. Most studies assume that the presynaptic axons are cholinergic extrinsic inputs to the slice that remain functional even when severed (i.e., they support action potentials and release transmitter). Interestingly, however, one study noted that because similar responses were seen in organotypic slice culture as in acute slices, it seems possible that cholinergic neurons intrinsic to the slicerather than severed axons that would not survive in a slice culture-mediate the synaptic response (Hefft et al. 1999). Putative cholinergic neurons are intrinsic to the neocortex, as well, but have been largely ignored in physiological studies. Finally, one study has provided evidence that stimulation of cholinergic pathways to the hippocampus acts via presynaptic $\alpha 7$ receptors to produce long-lasting increases in the probability of glutamate release (Maggi et al. 2003). Thus, endogenous ACh has been shown to act at both pre- and postsynaptic nAChRs in nonsensory cortex.

\section{nAChRs and Sensory Cortex Development}

A wealth of anatomical evidence accumulated over more than two decades points to a transient cholinergic function that occurs specifically in sensory neocortex during development. Initial studies focused on the distribution of staining for acetylcholinesterase (AChE), the cholinergic hydrolytic enzyme (Kristt 1979a,b). These studies reported a dense AChE staining primarily in layer 4 (but also in layers 1 and 6) of rat somatosensory cortex. The staining appeared shortly after birth, peaked in density over 1-2 wk, and was not apparent after postnatal day (P) 21 (although a different AChE laminar pattern, less dense, remains into adulthood). At its peak, the AChE density showed clearly outlined barrels in tangential sections through layer 4 . The areal, laminar, and temporal development of the AChE staining corresponded to that of thalamocortical afferents that reach layer 4 shortly after birth and proliferate over the subsequent $1-2 \mathrm{wk}$ (Catalano et al. 1991, 1996), leading to the proposal that the AChE marked ingrowing thalamocortical afferents. In support of this idea, cortical undercut reduced the AChE stain in layer 4 (Kristt 1979a); however, it is not clear why the dense layer 4 AChE staining disappears after the third postnatal week.

These initial findings subsequently were extended to the rat visual and auditory cortices (Robertson et al. 1985, 1991; Prusky et al. 1988). In both cortices, dense layer 4 AChE staining begins to appear in postnatal Week 1 , peaks in density during Week 2 , and is reduced to low (adult) levels after Week 3. The AChE in layer 4 of visual or auditory cortex was coextensive with transneuronal labeling of layer 4 with horseradish peroxidase (HRP) deposited in the eye (Kageyama et al. 1990) or inferior colliculus (Robertson et al. 1991), respectively, confirming the correlation with thalamocortical arbors. Similarly, lesion of the auditory pathway (medial geniculate or inferior colliculus), or enucleation of the eye, reduced AChE levels in layer 4 but not in other layers of auditory or visual cortex. Conversely, basal forebrain lesions that disrupted the cholinergic projection to the cortex reduced the AChE stain outside of, but not within, layer 4. It seems clear that dense AChE staining is associated with thalamocortical afferents during postnatal development of sensory cortex.

Other studies have shown that nicotine binding in layer 4 of sensory cortex also appears during postnatal development, but

\section{Learning \& Memory \\ www.learnmem.org}


the degree to which this mirrors the transient AChE staining is not clear. Studies in rat visual cortex showed that layer 4 nicotine binding transiently increased in Weeks $2-3$, and then either decreased in Week 4 to remain at low levels into adulthood (Kumar and Schliebs 1992) or returned to high levels in adulthood (Prusky et al. 1988). In the latter study, the adult layer 4 binding pattern extended throughout much of neocortex-that is, corresponding to the putative presynaptic $\alpha 4 \beta 2 \mathrm{nAChRs}$ associated with thalamocortical terminals (described in "Cellular Bases of Nicotinic Regulation of Sensory Cortex" above)whereas the Week 2 pattern was restricted to visual cortex (and, weakly, in auditory cortex; Prusky et al. 1988). Other studies indicate that cortical nicotine binding peaked later (Weeks 3-4 in the rat) and remained strong into adulthood (Sershen et al. 1982; Yamada et al. 1986; Slotkin et al. 1987; Naeff et al. 1992; Aubert et al. 1996). However, these latter studies did not always distinguish between sensory and nonsensory cortex, and may not have detected an early, transient increase in nicotine binding if it occurred only in sensory cortex. Thus, the nicotine binding in adult sensory cortex (presumed $\alpha 4 \beta 2 \mathrm{nAChRs)} \mathrm{is} \mathrm{apparent} \mathrm{late} \mathrm{in} \mathrm{post-}$ natal development, but its relationship to nicotine binding and transient AChE staining earlier in development remains unclear.

In contrast, additional studies point to a transient role for $\alpha 7$ nAChRs in sensory cortex development, one with a developmental time course that more closely parallels that of the AChE staining. In rat cortex, labeled $\alpha$ BTX binding appears in each sensory neocortex starting at P0, peaks around P10, at which point it delineates each primary sensory cortex, and then fades to lower (adult) levels by P20 (uniform low level distribution across sensory and nonsensory cortex; Fuchs 1989). At its peak, the laminar pattern shows two regions of high density, in layer 4 and layers $5 / 6$, whereas only weaker label in the deeper layers persists in the adult. More recent studies in the rat have shown a close developmental correlation of transient $\alpha \mathrm{BTX}$ binding, AChE staining, and expression of $\alpha 7$ mRNA in each sensory neocortex and the corresponding thalamic relay nuclei ${ }^{6}$ (Broide et al. 1995, 1996). In somatosensory cortex, all three measures coincide in layer 4, but only $\alpha$ BTX binding and $\alpha 7$ mRNA expression occur in layer 6 . Importantly, thalamic lesions were found to reduce cortical levels of $\alpha 7$ mRNA within hours, and before AChE staining decreased; because mRNA is expressed in cortical neurons, whereas AChE marks thalamocortical fibers, the authors suggest that some, at least, of the cortical $\alpha 7 \mathrm{nAChR}$ expression is postsynaptic and yet regulated by thalamocortical inputs. However, additional evidence-including a more discrete cortical label pattern for $\alpha$ BTX than for mRNA, and thalamic expression of $\alpha 7$ mRNAis consistent with a presynaptic function for $\alpha 7 \mathrm{nAChRs}$ in thalamocortical transmission (Broide et al. 1996). Thus, both pre- and postsynaptic $\alpha 7 \mathrm{nAChRs}$ may have transient roles in sensory cortex development.

Several studies support the relevance of the findings in these animal models to human sensory cortex development, but show that postnatal development in the rodent more closely resembles prenatal (third trimester) human development. In the developing human auditory system, AChE staining marks thalamocortical afferents as they emerge from the diencephalon and grow toward the auditory cortex (Krmpotic-Nemanic et al. 1983). Early in the third trimester ( Week 28 of gestation), the AChE forms densely stained zones in layer 4 of auditory cortex, delineating it from the surrounding temporal cortex (Krmpotic-Nemanic et al.

\footnotetext{
${ }^{6}$ Transient appearance of $\alpha 7$ mRNA and $\alpha \mathrm{BTX}$ binding also has been demonstrated in mouse somatosensory cortex, with a similar developmental time course and laminar distribution (Bina et al. 1995). However, these cortical markers are not accompanied by a corresponding expression in the thalamus, indicating a possible species difference.
}

1980). Notably, a similar species difference applies to the onset of sensory function: The rat begins to hear in postnatal Week 2 (Jewett and Romano 1972; Iwasa and Potsic 1982), whereas human hearing begins early in the third trimester (Moore 2002). Thus, auditory cortex development during postnatal Weeks 1-3 in the rat is similar to human third trimester development in terms of (1) growth and proliferation of thalamocortical inputs into layer 4, (2) dense AChE staining in layer 4, and (3) the onset of hearing. Some possible functional implications of this convergence of events are discussed below.

Despite the large number of anatomical reports suggestive of a transient cholinergic function in developing sensory cortex, a physiological examination was undertaken only recently. ${ }^{7}$ In a brain slice study of rat auditory cortex, nicotine $(0.5-25 \mu \mathrm{M})$ was pressure-ejected onto the dendrites of pyramidal neurons in layers 3-4 and found to modify their responses to afferent glutamatergic stimulation (Aramakis and Metherate 1998). Nicotine selectively enhanced the late, $N$-methyl-D-aspartate receptor (NMDAR) component of the EPSP without affecting the early, $\alpha$-amino-3-hydroxy-5-methyl-isoxazole-4-propionic acid receptor (AMPAR) component. Because MLA ( $5 \mathrm{nM}$ ) blocked the effect, as did preceding bath application of nicotine $(0.3-10 \mu \mathrm{M}$ for several minutes), and because nicotine did not enhance responses to iontophoretically applied glutamate, the effect was considered caused by rapidly desensitizing, presynaptic $\alpha 7$ nAChRs located on glutamatergic terminals ${ }^{8}$ (Fig. 1A). Developmentally, the effect occurred most frequently ( $\sim 90 \%$ of neurons tested) early in Week 2 in brains that had visible AChE staining in auditory cortex, and rarely ( $\sim 6 \%)$ after the middle of Week 3 when the AChE staining had disappeared. Although the nicotinic enhancement of the NMDAR EPSP was more frequent before P12, the magnitude of the enhancement in individual neurons was significantly greater after P12 (Metherate and Hsieh 2003), a transition that may be related to the onset of hearing (Fig. 1C). (In a related note, it has been shown that the frequency of spontaneous EPSCs mediated by nAChRs in ferret visual cortex increases dramatically at the time of eye opening; Roerig et al. 1997).

To explain how presynaptic $\alpha 7$ receptors could selectively enhance postsynaptic responses mediated by NMDARs, but not AMPARs, it was proposed that glutamate synapses regulated by presynaptic nAChRs had only NMDARs postsynaptically ("pureNMDAR" synapses; Fig. 1A), whereas other glutamate synapses had AMPARs (and/or NMDARs) postsynaptically but no presynaptic nAChRs; Aramakis and Metherate 1998; Metherate and Hsieh 2003). Pure-NMDAR synapses, often called silent synapses, occur in developing sensory cortex and are thought to be converted to mature synapses with activity (depolarization)dependent insertion of AMPARs (Isaac et al. 1997; Rumpel et al. 1998). We speculate that release of ACh in auditory cortex, for

\footnotetext{
${ }^{7}$ As mentioned above, most physiological studies on brain slices use tissue from young rodents ( 2 to 3 weeks old) for ease of recording. Although this is a relevant developmental period for the issues being considered here, the in vitro studies of nAChRs typically are not explicitly developmental, that is, the data are grouped together rather than split by age, and they bear unknown relationships to the age-related changes in cholinergic markers. Most of the results have been discussed above, and will not be repeated here unless clearly relevant to development.

${ }^{8}$ In most neurons, nicotine applied by itself did not produce a postsynaptic response, but instead modified the response to afferent stimulation (Aramakis and Metherate 1998). However, in a minority $(<20 \%)$ of neurons, the first application of nicotine by itself produced a rapid, robust postsynaptic depolarization. This effect was difficult to study, because it required many minutes to recover from presumed $n A C h R$ desensitization, in contrast to the nicotinic enhancement of EPSPs, which recovered within seconds. Thus, the nature of the direct nicotine effect is unknown, but may involve postsynaptic nAChRs for which anatomical evidence was described above (Broide et al. 1996; Levy and Aoki 2002).
} 
example, during attention to behaviorally relevant sounds, may increase glutamate release at active synapses and facilitate their conversion to mature synapses with AMPARs (Fig. 1A). Such maturation would be expected to result in the loss of presynaptic $\alpha 7 \mathrm{nAChRs}$ (because nicotine did not enhance release at synapses containing AMPARs during development), and possibly, the eventual appearance of presynaptic $\alpha 4 \beta 2 \mathrm{nAChRs}$ in the adult (Fig. 1B,C). Thus, according to this hypothesis, $\alpha 7 \mathrm{nAChR}-$ mediated regulation of NMDAR synapses would be critical to experience-dependant maturation of cortical circuitry. It is relevant to note that $\alpha 7$ receptors have been implicated in several processes involving synapse development (Role and Berg 1996; Broide and Leslie 1999).

\section{Related Findings in Nonsensory Cortex}

A study mentioned in the previous section (Maggi et al. 2003) describes presynaptic $\alpha 7$ receptors in the neonatal hippocampus that, when activated, convert "silent" synapses to more mature synapses. However, the mechanism is different from that proposed here for auditory cortex, in that the synapses are presynaptically silent-insufficient glutamate is released to activate postsynaptic AMPARs-until $\alpha 7$ receptor stimulation results in a long-lasting increase in the probability of release. Also, interactions involving NMDARs and $\alpha 7$ nAChRs have been demonstrated in embryonic cortical neurons (Jensen et al. 1997) and hippocampal interneurons (Alkondon et al. 2003), but these do not seem closely related to interactions observed in sensory cortex.

\section{Does the Transient, $\alpha 7$ nAChR-Mediated Regulation of Auditory Cortex Define a Critical Period?}

A large body of evidence indicates that cholinergic and glutamatergic processes may contribute to postnatal critical periods initiated by the onset of sensory function, although most studies have focused on muscarinic ACh receptors or NMDARs (Bear and Singer 1986; Hohmann and Berger-Sweeney 1998; Fox et al. 1999; Yuste and Sur 1999). The studies reviewed here raise another possibility, one involving nAChRs and NMDARs. In the rat, the onset of hearing in Week 2 occurs at the height of $\alpha 7$ receptor-mediated regulation of NMDAR synapses in auditory cortex (Fig. 1C). Thus, this regulation may contribute to experience-dependent synaptogenesis and neural circuit formation. A clear implication of this hypothesis is that manipulating nAChR function should also affect the development of glutamate synapses and sensory function. To test this, rat pups were treated with chronic nicotine exposure (CNE; $0.35-0.7 \mathrm{mg} / \mathrm{kg}$ nicotine s.c. twice daily for 5-9 d; Aramakis et al. 2000). CNE during Week 2-but not during Weeks 1 or 4-altered glutamate synapse development dramatically: EPSPs after Week 2 CNE had longer durations and unusual, small fluctuations that may reflect altered mechanisms of release or hyperexcitable synaptic circuitry. Consistent with the hypothesized location of nAChRs at pureNMDAR synapses, CNE altered only the NMDAR component of EPSPs-roughly doubling the magnitude of this componentbut did not affect the AMPAR component. Thus, postnatal Week 2 in the rat appears to be a sensitive or critical period, as least regarding exposure to exogenous nicotine.

In another test of the hypothesis, CNE has been shown to affect NMDAR development in auditory cortex. CNE altered the developmental expression of mRNA for NMDAR subunits (Hsieh et al. 2002), and prevented the normal maturation and disappearance of pure-NMDAR synapses (Hsieh and Metherate 2003). These effects of CNE may reflect disruption of the normal role of nAChRs in the development of NMDARs. Finally, in preliminary studies to determine the effect of early postnatal manipulations on sensory function, CNE during Week 2 markedly reduced the ability of systemic nicotine to enhance sensory responsiveness in adult (>2-month-old) auditory cortex (Liang and Metherate 2003; cf. "Cortical nAChRs Regulate Responses to Sensory Stimuli" above). These data indicate that early postnatal CNE can lead to nAChR dysfunction in adult animals.

The effects of CNE in the rat should be related to human development, especially in light of the possible consequences for brain development of nicotine exposure from cigarette smoking. The studies reviewed here raise the possibility that maternal smoking may alter fetal sensory cortex development, with potentially long-lasting consequences. Notably, infants born to mothers who smoke during pregnancy show auditory-related cognitive deficits as they mature, despite apparent normal hearing range and thresholds (Sexton et al. 1990; McCartney et al. 1994; Fried et al. 1997). It is possible that CNE-induced disruption of developing NMDARs and nAChR function may contribute to sensory-cognitive deficits in older children and adults.

\section{Conclusions and Some Future Directions}

A consensus is emerging on some likely functions of nAChRs in sensory neocortex. Cortical nAChRs likely act to enhance sensory responsiveness, which may contribute to improved behavioral performance in sensory-cognitive tasks. The cellular basis for this may lie in the regulation of thalamocortical glutamate release by presynaptic (or preterminal) nAChRs (Fig. 1B), and possibly in nicotinic regulation of GABAergic interneurons. Although the latter effect is clear experimentally, its consequences for sensory processing depend on how interneurons contribute to cortical circuits activated by sensory stimuli. Such a problem will be technically difficult to answer; however, it may be simplified through the use of reduced preparations, such as the thalamocortical slice.

The major roles of nAChRs identified thus far in sensory cortex appear, at first glance, similar to some roles in nonsensory cortex, which supports the idea of sensory cortex as a useful model system (given that physiological activation with sensory stimuli is possible). A clear example of correspondence between sensory and nonsensory cortex is the nAChR-mediated regulation of thalamocortical afferents in prefrontal cortex: The cellular mechanisms seem similar to those in sensory cortex, although the function of prefrontal cortex is undoubtedly quite different. Nicotinic actions in sensory cortex and hippocampus also exhibit broad similarities, for example, prominent nicotinic excitation of GABAergic interneurons. However, differences in the underlying mechanisms (e.g., nAChR subtypes) and obvious differences in circuitry preclude simple analogies at the systems level. Nonetheless, understanding the role of nAChRs in regulating sensory cortical responses to sensory stimuli should contribute to the understanding of systems-level function in other cortices.

Finally, recent studies have identified novel nAChR functions during postnatal development of sensory cortex (Fig. 1A,C). These occur at the onset of sensory function, and may define a critical period, that is, they may contribute to the shaping of synaptic circuitry by early sensory experience. Ongoing research indicates that transient exposure to exogenous nicotine during this critical period may permanently alter sensory cortex function. Such effects may underlie the sensory-cognitive deficits in children exposed prenatally to nicotine. It will be necessary to pursue both human and animal studies to test the possible link between developmental nicotine exposure and subsequent cognitive function.

\section{ACKNOWLEDGMENTS}

Thanks to H. Kawai, F.M. Leslie, R.T. Robertson, and K. Liang for helpful comments and discussions regarding this manuscript. Re- 
search from my laboratory reported here has been supported by NIDA (DA12929), NIDCD (DC02967), and the California Tobacco-Related Disease Research Program (8RT-0059).

\section{REFERENCES}

Adler, L.E., Olincy, A., Waldo, M., Harris, J.G., Griffith, J., Stevens, K., Flach, K., Nagamoto, H., Bickford, P., Leonard, S., et al. 1998. Schizophrenia, sensory gating, and nicotinic receptors. Schizophr. Bull. 24: $189-202$.

Agmon, A. and Connors, B.W. 1991. Thalamocortical responses of mouse somatosensory (barrel) cortex in vitro. Neuroscience 41: $365-379$.

Alkondon, M. and Albuquerque, E.X. 2001. Nicotinic acetylcholine receptor $\alpha 7$ and $\alpha 4 \beta 2$ subtypes differentially control GABAergic input to CA1 neurons in rat hippocampus. J. Neurophysiol. 86: 3043-3055.

. 2003. The nicotinic acetylcholine receptor subtypes and their function in the hippocampus and cerebral cortex. Prog. Brain Res. 145: $109-120$.

Alkondon, M., Pereira, E.F., Cortes, W.S., Maelicke, A., and Albuquerque, E.X. 1997. Choline is a selective agonist of $\alpha 7$ nicotinic acetylcholine receptors in the rat brain neurons. Eur. J. Neurosci. 9: $2734-2742$.

Alkondon, M., Pereira, E.F., and Albuquerque, E.X. 1998. $\alpha$-Bungarotoxin- and methyllycaconitine-sensitive nicotinic receptors mediate fast synaptic transmission in interneurons of rat hippocampal slices. Brain Res. 810: 257-263.

Alkondon, M., Pereira, E.F., Almeida, L.E., Randall, W.R., and Albuquerque, E.X. 2000. Nicotine at concentrations found in cigarette smokers activates and desensitizes nicotinic acetylcholine receptors in CA1 interneurons of rat hippocampus. Neuropharmacology 39: 2726-2739.

Alkondon, M., Pereira, E.F., and Albuquerque, E.X. 2003. NMDA and AMPA receptors contribute to the nicotinic cholinergic excitation of CA1 interneurons in the rat hippocampus. J. Neurophysiol. 90: $1613-1625$.

Aramakis, V.B. and Metherate, R. 1998. Nicotine selectively enhances NMDA receptor-mediated synaptic transmission during postnatal development in sensory neocortex. J. Neurosci. 18: 8485-8495.

Aramakis, V.B., Hsieh, C.Y., Leslie, F.M., and Metherate, R. 2000. A critical period for nicotine-induced disruption of synaptic development in rat auditory cortex. J. Neurosci. 20: 6106-6116.

Aubert, I., Cecyre, D., Gauthier, S., and Quirion, R. 1996. Comparative ontogenic profile of cholinergic markers, including nicotinic and muscarinic receptors, in the rat brain. J. Comp. Neurol. 369: 31-55.

Azam, L., Winzer-Serhan, U., and Leslie, F.M. 2003. Co-expression of $\alpha 7$ and $\beta 2$ nicotinic acetylcholine receptor subunit mRNAs within rat brain cholinergic neurons. Neuroscience 119: 965-977.

Bear, M.F. and Singer, W. 1986. Modulation of visual cortical plasticity by acetylcholine and noradrenaline. Nature 320: 172-176.

Benowitz, N.L. 1996. Pharmacology of nicotine: Addiction and therapeutics. Annu. Rev. Pharmacol. Toxicol. 36: 597-613.

Bhargava, V.K., Salamy, A., and Mckean, C.M. 1978. Effects of cholinergic drugs on auditory evoked responses (CER) of rat cortex. Neuropharmacology 17: 1009-1013.

Bina, K.G., Guzman, P., Broide, R.S., Leslie, F.M., Smith, M.A., and O'Dowd, D.K. 1995. Localization of $\alpha 7$ nicotinic receptor subunit mRNA and $\alpha$ - bungarotoxin binding sites in developing mouse somatosensory thalamocortical system. J. Comp. Neurol. 363: 321-332.

Blanton, M.G., LoTurco, J.J., and Kriegstein, A.R. 1989. Whole cell recording from neurons in slices of reptilian and mammalian cerebral cortex. J. Neurosci. Meth. 30: 203-210.

Bringmann, A. 1994. Behaviour-related effects of physostigmine on the rat visual evoked potential. Acta Neurobiol. Exp. (Warsz) 54: 355-363.

Broide, R.S. and Leslie, F.M. 1999. The $\alpha 7$ nicotinic acetylcholine receptor in neuronal plasticity. Mol. Neurobiol. 20: 1-16.

Broide, R.S., O'Connor, L.T., Smith, M.A., Smith, J.A.M., and Leslie, F.M. 1995. Developmental expression of $\alpha 7$ neuronal nicotinic receptor messenger RNA in rat sensory cortex and thalamus. Neuroscience 67: 83-94.

Broide, R.S., Robertson, R.T., and Leslie, F.M. 1996. Regulation of $\alpha-7$ nicotinic acetylcholine receptors in the developing rat somatosensory cortex by thalamocortical afferents. J. Neurosci. 16: $2956-2971$.

Castro, N.G. and Albuquerque, E.X. 1995. The $\alpha$-bungarotoxin-sensitive hippocampal nicotinic receptor channel has a high calcium permeability. Biophys. J. 68: 516-524.

Catalano, S.M., Robertson, R.T., and Killackey, H.P. 1991. Early ingrowth of thalamocortical afferents to the neocortex of the prenatal rat. Proc. Natl. Acad. Sci. 88: 2999-3003.

. 1996. Individual axon morphology and thalamocortical topography in developing rat somatosensory cortex. J. Comp. Neurol. 367: 36-53.

Celesia, G.G. and Jasper, H.H. 1966. Acetylcholine released from cerebral cortex in relation to state of activation. Neurology (Minneap.) 16: $1053-1070$.

Christophe, E., Roebuck, A., Staiger, J.F., Lavery, D.J., Charpak, S., and Audinat, E. 2002. Two types of nicotinic receptors mediate an excitation of neocortical layer I interneurons. J. Neurophysiol. 88: $1318-1327$

Chu, Z.G., Zhou, F.M., and Hablitz, J.J. 2000. Nicotinic acetylcholine receptor-mediated synaptic potentials in rat neocortex. Brain Res. 887: 399-405.

Clarke, P.B.S. 2003. Nicotinic modulation of thalamocortical neurotransmission. Prog. Brain Res. 145: 253-260.

Clarke, P.B., Pert, C.B., and Pert, A. 1984. Autoradiographic distribution of nicotine receptors in rat brain. Brain Res. 323: 390-395.

Clarke, P.B., Schwartz, R.D., Paul, S.M., Pert, C.B., and Pert, A. 1985. Nicotinic binding in rat brain: Autoradiographic comparison of $\left[{ }^{3} \mathrm{H}\right]$ acetylcholine, $\left[{ }^{3} \mathrm{H}\right]$ nicotine, and $\left[{ }^{125} \mathrm{I}\right]-\alpha$-bungarotoxin. $J$. Neurosci. 5: 1307-1315.

Couturier, S., Bertrand, D., Matter, J.M., Hernandez, M.C., Bertrand, S., Millar, N., Valera, S., Barkas, T., and Ballivet, M. 1990. A neuronal nicotinic acetylcholine receptor subunit $(\alpha 7)$ is developmentally regulated and forms a homo-oligomeric channel blocked by $\alpha$-BTX. Neuron 5: 847-856.

Crooks, P.A. and Dwoskin, L.P. 1997. Contribution of CNS nicotine metabolites to the neuropharmacological effects of nicotine and tobacco smoking. Biochem. Pharmacol. 54: 743-753.

Cruikshank, S.J., Rose, H.J., and Metherate, R. 2002. Auditory thalamocortical synaptic transmission, in vitro. J. Neurophysiol. 87: $361-384$.

Dani, J.A. 2001. Overview of nicotinic receptors and their roles in the central nervous system. Biol. Psychiatry 49: 166-174.

Dani, J.A. and Heinemann, S. 1996. Molecular and cellular aspects of nicotine abuse. Neuron 16: $905-908$.

Dodt, H.-U. and Zieglgansberger, W. 1990. Visualizing unstained neurons in living brain slices by infrared DIC-videomicroscopy. Brain Res. 537: 333-336.

Domino, E.F., Minoshima, S., Guthrie, S., Ohl, L., Ni, L., Koeppe, R.A., and Zubieta, J.K. 2000. Nicotine effects on regional cerebral blood flow in awake, resting tobacco smokers. Synapse 38: 313-321.

Dykes, R.W. 1997. Mechanisms controlling neuronal plasticity in somatosensory cortex. Can. J. Physiol. Pharmacol. 75: 535-545.

Edeline, J.M. 1999. Learning-induced physiological plasticity in the thalamo-cortical sensory systems: A critical evaluation of receptive field plasticity, map changes and their potential mechanisms. Prog. Neurobiol. 57: 165-224.

Ernst, M., Moolchan, E.T., and Robinson, M.L. 2001. Behavioral and neural consequences of prenatal exposure to nicotine. J. Am. Acad. Child Adolesc. Psychiatry 40: 630-641.

Fenster, C.P., Rains, M.F., Noerager, B., Quick, M.W., and Lester, R.A. 1997. Influence of subunit composition on desensitization of neuronal acetylcholine receptors at low concentrations of nicotine. I. Neurosci. 17: 5747-5759.

Ferezou, I., Cauli, B., Hill, E.L., Rossier, J., Hamel, E., and Lambolez, B. 2002. $5-\mathrm{HT}_{3}$ receptors mediate serotonergic fast synaptic excitation of neocortical vasoactive intestinal peptide/cholecystokinin interneurons. J. Neurosci. 22: 7389-7397.

Fox, K., Henley, J., and Isaac, J. 1999. Experience-dependent development of NMDA receptor transmission. Nat. Neurosci. 2: 297-299.

Frazier, C.J., Buhler, A.V., Weiner, J.L., and Dunwiddie, T.V. 1998a Synaptic potentials mediated via $\alpha$-bungarotoxin-sensitive nicotinic acetylcholine receptors in rat hippocampal interneurons. J. Neurosci. 18: $8228-8235$

Frazier, C.J., Rollins, Y.D., Breese, C.R., Leonard, S., Freedman, R., and Dunwiddie, T.V. 1998b. Acetylcholine activates an $\alpha$-bungarotoxin-sensitive nicotinic current in rat hippocampal interneurons, but not pyramidal cells. J. Neurosci. 18: 1187-1195.

Frazier, C.J., Strowbridge, B.W., and Papke, R.L. 2003. Nicotinic receptors on local circuit neurons in dentate gyrus: A potential role in regulation of granule cell excitability. J. Neurophysiol. 89: 3018-3028.

Freedman, R., Adams, C.E., and Leonard, S. 2000. The $\alpha 7$-nicotinic acetylcholine receptor and the pathology of hippocampal interneurons in schizophrenia. J. Chem. Neuroanat. 20: 299-306.

Fried, P.A. and Watkinson, B. 2001. Differential effects on facets of attention in adolescents prenatally exposed to cigarettes and marihuana. Neurotoxicol. Teratol. 23: 421-430.

Fried, P.A., Watkinson, B., and Siegel, L.S. 1997. Reading and language in 9- to 12-year olds prenatally exposed to cigarettes and marijuana. Neurotoxicol. Teratol. 19: 171-183. 
Friedman, J. and Meares, R. 1980. Tobacco smoking and cortical evoked potentials: An opposite effect on auditory and visual systems. Clin. Exp. Pharmacol. Physiol. 7: 609-615.

Fuchs, J.L. 1989. $\left[{ }^{125} \mathrm{I}\right] \alpha$-Bungarotoxin binding marks primary sensory areas of developing rat neocortex. Brain Res. 501: 223-234.

Gil, Z., Connors, B.W., and Amitai, Y. 1997. Differential regulation of neocortical synapses by neuromodulators and activity. Neuron 19: 679-686.

Gioanni, Y., Rougeot, C., Clarke, P.B., Lepouse, C., Thierry, A.M., and Vidal, C. 1999. Nicotinic receptors in the rat prefrontal cortex: Increase in glutamate release and facilitation of mediodorsa thalamo-cortical transmission. Eur. J. Neurosci. 11: 18-30.

Granon, S., Poucet, B., Thinus-Blanc, C., Changeux, J.P., and Vidal, C. 1995. Nicotinic and muscarinic receptors in the rat prefrontal cortex: Differential roles in working memory, response selection and effortful processing. Psychopharmacology (Berl) 119: 139-144

Gray, R., Rajan, A.S., Radcliffe, K.A., Yakehiro, M., and Dani, J.A. 1996. Hippocampal synaptic transmission enhanced by low concentrations of nicotine. Nature 383: 713-716.

Guha, D. and Pradhan, S.N. 1976. Effects of nicotine on EEG and evoked potentials and their interactions with autonomic drugs. Neuropharmacology 15: 225-232.

Hall, R.A., Rappaport, M., Hopkins, H.K., and Griffin, R. 1973. Tobacco and evoked potential. Science 180: $212-214$.

Harkrider, A.W. and Champlin, C.A. 2001a. Acute effect of nicotine on non-smokers: II. MLRs and 40-Hz responses. Hear. Res. 160: 89-98.

. 2001b. Acute effect of nicotine on non-smokers: III. LLRs and EEGs. Hear. Res. 160: $99-110$.

Harkrider, A.W., Champlin, C.A., and McFadden, D. 2001. Acute effect of nicotine on non-smokers: I. OAEs and ABRs. Hear. Res. 160: 73-88.

Hefft, S., Hulo, S., Bertrand, D., and Muller, D. 1999. Synaptic transmission at nicotinic acetylcholine receptors in rat hippocampal organotypic cultures and slices. J. Physiol. 515 (Pt 3): 769-776.

Henningfield, J.E., Stapleton, J.M., Benowitz, N.L., Grayson, R.F., and London, E.D. 1993. Higher levels of nicotine in arterial than in venous blood after cigarette smoking. Drug Alcohol Depend. 33: 23-29.

Hohmann, C.F. and Berger-Sweeney, J. 1998. Cholinergic regulation of cortical development and plasticity. New twists to an old story. Perspect. Dev. Neurobiol. 5: 401-425.

Hsieh, C.Y. and Metherate, R. 2003. Postnatal nicotine exposure alters development of NMDAR-mediated EPSCs in rat auditory cortex. Soc. Neurosci. Abstr. 29: 323-324.

Hsieh, C.Y., Leslie, F.M., and Metherate, R. 2002. Nicotine exposure during a postnatal critical period alters NR2A and NR2B mRNA expression in rat auditory forebrain. Dev. Brain Res. 133: 19-25.

Isaac, J.T.R., Crair, M.C., Nicoll, R.A., and Malenka, R.C. 1997. Silent synapses during development of thalamocortical inputs. Neuron 18: $269-280$.

Isaac, P.F. and Rand, M.J. 1972. Cigarette smoking and plasma levels of nicotine. Nature 236: 308-310.

Iwasa, H. and Potsic, W.P. 1982. Maturational change of early, middle, and late components of the auditory evoked responses in rats. Otolaryngol. Head Neck Surg. 90: 95-102.

Jensen, J.J., Winzer-Serhan, U.H., and Leslie, F.M. 1997. Glial regulation of $\alpha$ 7-type nicotinic acetylcholine receptor in cultured rat cortical neurons. J. Neurochem. 68: 112-120.

Jewett, D.L. and Romano, M.N. 1972. Neonatal development of auditory system potentials averaged from the scalp of rat and cat. Brain Res. 36: 101-115.

Ji, D. and Dani, J.A. 2000. Inhibition and disinhibition of pyramidal neurons by activation of nicotinic receptors on hippocampal interneurons. J. Neurophysiol. 83: 2682-2690.

Ji, D., Lape, R., and Dani, J.A. 2001. Timing and location of nicotinic activity enhances or depresses hippocampal synaptic plasticity. Neuron 31: 131-141.

Jones, S. and Yakel, J.L. 1997. Functional nicotinic ACh receptors on interneurones in the rat hippocampus. J. Physiol. 504 (Pt 3): 603-610.

Jones, S., Sudweeks, S., and Yakel, J.L. 1999. Nicotinic receptors in the brain: Correlating physiology with function. Trends Neurosci. 22: $555-561$.

Kageyama, G.H., Gallivan, M.E., Gallardo, K.A., and Robertson, R.T. 1990. Relationships between patterns of acetylcholinesterase activity and geniculocortical terminal fields in developing and mature rat visual cortex. Dev. Brain Res. 53: 139-144.

Kishimoto, T. and Domino, E.F. 1998. Effects of tobacco smoking and abstinence on middle latency auditory evoked potentials. Clin. Pharmacol. Ther. 63: 571-579.

Kristt, D.A. 1979a. Somatosensory cortex: Acetylcholinesterase staining of barrel neuropil in the rat. Neurosci. Lett. 12: 177-182.

. 1979b. Development of neocortical circuitry: Histochemical localization of acetylcholinesterase in relation to the cell layers of rat somatosensory cortex. J. Comp. Neurol. 186: 1-15.

Krmpotic-Nemanic, J., Kostovic, I., Kelovic, Z., and Nemanic, D. 1980. Development of acetylcholinesterase (AChE) staining in human fetal auditory cortex. Acta Otolaryngol. 89: 388-392.

Krmpotic-Nemanic, J., Kostovic, I., Kelovic, Z., Nemanic, D., and Mrzljak, L. 1983. Development of the human fetal auditory cortex: Growth of afferent fibers. Acta Anat. 116: 69-73.

Krnjevic, K. and Phillis, J.W. 1963. Iontophoretic studies of neurones in the mammalian cerebral cortex. J. Physiol. (Lond.) 165: 274-304.

Kumar, A. and Schliebs, R. 1992. Postnatal laminar development of cholinergic receptors, protein kinase $C$ and dihydropyridine-sensitive calcium antagonist binding in rat visual cortex. Effect of visual deprivation. Int. J. Dev. Neurosci. 10: 491-504.

Lambe, E.K., Picciotto, M.R., and Aghajanian, G.K. 2003. Nicotine induces glutamate release from thalamocortical terminals in prefrontal cortex. Neuropsychopharmacology 28: 216-225.

Lamour, Y., Dutar, P., and Jobert, A. 1982. Excitatory effect of acetylcholine on different types of neurons in the first somatosensory neocortex of the rat: laminar distribution and pharmacological characteristics. Neuroscience 7: 1483-1494.

Lavine, N., Reuben, M., and Clarke, P.B.S. 1997. A population of nicotine receptors is associated with thalamocortical afferents in the adult rat: Laminar and areal analysis. J. Comp. Neurol. 380: $175-190$.

Leonard, S. and Bertrand, D. 2001. Neuronal nicotinic receptors: From structure to function. Nicotine Tob. Res. 3: 203-223.

Levy, R.B. and Aoki, C. 2002. $\alpha 7$ nicotinic acetylcholine receptors occur at postsynaptic densities of AMPA receptor-positive and -negative excitatory synapses in rat sensory cortex. J. Neurosci. 22: 5001-5015.

Lewandowski, M.H., Muller, C.M., and Singer, W. 1993. Reticular facilitation of cat visual cortical responses is mediated by nicotinic and muscarinic cholinergic mechanisms. Exp. Brain Res. 96: 1-7.

Liang, K. and Metherate, R. 2003. Postnatal nicotine exposure attenuates adult nAChR function in rat auditory cortex in vivo. Soc. Neurosci. Abstr. 29: 323-325.

London, E.D., Waller, S.B., and Wamsley, J.K. 1985. Autoradiographic localization of $\left[{ }^{3} \mathrm{H}\right]$ nicotine binding sites in the rat brain. Neurosci. Lett. 53: 179-184.

Maggi, L., Magueresse, C.L., Changeux, J.P., and Cherubini, E. 2003. Nicotine activates immature "silent" connections in the developing hippocampus. Proc. Natl. Acad. Sci. 100: 2059-2064.

McCartney, J.S., Fried, P.A., and Watkinson, B. 1994. Central auditory processing in school-age children prenatally exposed to cigarette smoke. Neurotoxicol. Teratol. 16: 269-276.

Mechawar, N., Cozzari, C., and Descarries, L. 2000. Cholinergic innervation in adult rat cerebral cortex: A quantitative immunocytochemical description. J. Comp. Neurol. 428: 305-318.

Metherate, R. and Ashe, J.H. 1993. Nucleus basalis stimulation facilitates thalamocortical synaptic transmission in rat auditory cortex. Synapse 14: $132-143$.

. 1995. Synaptic interactions involving acetylcholine, glutamate and GABA in rat auditory cortex. Exp. Brain Res. 107: 59-72.

Metherate, R. and Hsieh, C.Y. 2003. Synaptic mechanisms and cholinergic regulation in auditory cortex. Prog. Brain Res. 145: $143-156$.

Moore, D.R. 2002. Auditory development and the role of experience. $\mathrm{Br}$. Med. Bull. 63: 171-181.

Morley, B.J. and Happe, H.K. 2000. Cholinergic receptors: Dual roles in transduction and plasticity. Hear. Res. 147: 104-112.

Naeff, B., Schlumpf, M., and Lichtensteiger, W. 1992. Pre- and postnatal development of high-affinity $\left[{ }^{3} \mathrm{H}\right]$ nicotine binding sites in rat brain regions: An autoradiographic study. Dev. Brain Res. 68: 163-174.

Oldford, E. and Castro-Alamancos, M.A. 2003. Input-specific effects of acetylcholine on sensory and intracortical evoked responses in the "barrel cortex" in vivo. Neuroscience 117: 769-778.

Oncken, C.A. and Kranzler, H.R. 2003. Pharmacotherapies to enhance smoking cessation during pregnancy. Drug Alcohol Rev. 22: 191-202.

Parkinson, D., Kratz, K.E., and Daw, N.W. 1988. Evidence for a nicotinic component to the actions of acetylcholine in cat visual cortex. Exp. Brain Res. 73: 553-568.

Penschuck, S., Chen-Bee, C.H., Prakash, N., and Frostig, R.D. 2002. In vivo modulation of a cortical functional sensory representation shortly after topical cholinergic agent application. J. Comp. Neurol. 452: $38-50$.

Phillis, J.W. 1968. Acetylcholine release from the cerebral cortex: Its role in cortical arousal. Brain Res. 7: 378-389.

Porter, J.T., Cauli, B., Tsuzuki, K., Lambolez, B., Rossier, J., and Audinat, E. 1999. Selective excitation of subtypes of neocortical interneurons by nicotinic receptors. J. Neurosci. 19: 5228-5235.

Prusky, G.T., Shaw, C., and Cynader, M.S. 1987. Nicotine receptors are located on lateral geniculate nucleus terminals in cat visual cortex. 
Brain Res. 412: 131-138.

Prusky, G.T., Arbuckle, J.M., and Cynader, M.S. 1988. Transient concordant distributions of nicotinic receptors and acetylcholinesterase activity in infant rat visual cortex. Brain Res. 467: 154-159.

Radcliffe, K.A. and Dani, J.A. 1998. Nicotinic stimulation produces multiple forms of increased glutamatergic synaptic transmission. $J$. Neurosci. 18: 7075-7083.

Radcliffe, K.A., Fisher, J.L., Gray, R., and Dani, J.A. 1999. Nicotinic modulation of glutamate and GABA synaptic transmission of hippocampal neurons. Ann. NY Acad. Sci. 868: 591-610.

Raggenbass, M. and Bertrand, D. 2002. Nicotinic receptors in circuit excitability and epilepsy. J. Neurobiol. 53: 580-589.

Rasmusson, D.D. 2000. The role of acetylcholine in cortical synaptic plasticity. Behav. Brain. Res. 115: 205-218.

Rasmusson, D.D., Clow, K., and Szerb, J.C. 1994. Modification of neocortical acetylcholine release and electroencephalogram desynchronization due to brainstem stimulation by drugs applied to the basal forebrain. Neuroscience 60: 665-677.

Rezvani, A.H., Bushnell, P.J., and Levin, E.D. 2002. Effects of nicotine and mecamylamine on choice accuracy in an operant visual signal detection task in female rats. Psychopharmacology (Berl) 164: 369-375.

Robertson, R.T., Tijerina, A.A., and Gallivan, M.E. 1985. Transient patterns of acetylcholinesterase activity in visual cortex of the rat: Normal development and the effects of neonatal monocular enucleation. Brain Res. 353: 203-214.

Robertson, R.T., Mostamand, F., Kageyama, G.H., Gallardo, K.A., and $\mathrm{Yu}$, J. 1991. Primary auditory cortex in the rat: Transient expression of acetylcholinesterase in developing geniculocortical projections. Dev. Brain Res. 58: 81-95.

Roerig, B., Nelson, D.A., and Katz, L.C. 1997. Fast synaptic signaling by nicotinic acetylcholine and serotonin $5-\mathrm{HT}_{3}$ receptors in developing visual cortex. J. Neurosci. 17: 8353-8362.

Role, L.W. and Berg, D.K. 1996. Nicotinic receptors in the development and modulation of CNS synapses. Neuron 16: 1077-1085.

Rumpel, S., Hatt, H., and Gottmann, K. 1998. Silent synapses in the developing rat visual cortex: Evidence for postsynaptic expression of synaptic plasticity. J. Neurosci. 18: 8863-8874.

Rye, D.B., Wainer, B.H., Mesulam, M.M., Mufson, E.J., and Saper, C.B. 1984. Cortical projections arising from the basal forebrain: A study of cholinergic and noncholinergic components employing combined retrograde tracing and immunohistochemical localization of choline acetyltransferase. Neuroscience 13: 627-643.

Sahin, M., Bowen, W.D., and Donoghue, J.P. 1992. Location of nicotinic and muscarinic cholinergic and $\mu$-opiate receptors in rat cerebral neocortex: Evidence from thalamic and cortical lesions. Brain Res. 579: $135-147$.

Sarter, M., Givens, B., and Bruno, J.P. 2001. The cognitive neuroscience of sustained attention: Where top-down meets bottom-up. Brain Res. Rev. 35: 146-160.

Seguela, P., Wadiche, J., Dineley-Miller, K., Dani, J.A., and Patrick, J.W. 1993. Molecular cloning, functional properties, and distribution of rat brain $\alpha 7$ : A nicotinic cation channel highly permeable to calcium. J. Neurosci. 13: 596-604.

Sershen, H., Reith, M.E., Banay-Schwartz, M., and Lajtha, A. 1982. Effects of prenatal administration of nicotine on amino acid pools, protein metabolism, and nicotine binding in the brain. Neurochem. Res. 7: 1515-1522.
Sexton, M., Fox, N.L., and Hebel, J.R. 1990. Prenatal exposure to tobacco: II. Effects on cognitive functioning at age three. Int. J. Epidemiol. 19: 72-77.

Shao, Z. and Yakel, J.L. 2000. Single channel properties of neuronal nicotinic ACh receptors in stratum radiatum interneurons of rat hippocampal slices. J. Physiol. 527 Pt 3: 507-513.

Sharma, G. and Vijayaraghavan, S. 2003. Modulation of presynaptic store calcium induces release of glutamate and postsynaptic firing. Neuron 38: 929-939.

Shute, C.C.D. and Lewis, P.R. 1967. The ascending cholinergic reticular system: Neocortical, olfactory and subcortical projections. Brain 90: $497-520$.

Slotkin, T.A., Orband-Miller, L., and Queen, K.L. 1987. Development of $\left[{ }^{3} \mathrm{H}\right]$ nicotine binding sites in brain regions of rats exposed to nicotine prenatally via maternal injections or infusions. J. Pharmacol. Exp. Ther. 242: 232-237.

Stone, T.W. 1972. Cholinergic mechanisms in the rat somatosensory cerebral cortex. J. Physiol. 225: 485-499.

Turchi, J., Holley, L.A., and Sarter, M. 1995. Effects of nicotinic acetylcholine receptor ligands on behavioral vigilance in rats Psychopharmacology (Berl) 118: 195-205.

Turrini, P., Casu, M.A., Wong, T.P., De Koninck, Y., Ribeiro-da-Silva, A., and Cuello, A.C. 2001. Cholinergic nerve terminals establish classical synapses in the rat cerebral cortex: Synaptic pattern and age-related atrophy. Neuroscience 105: 277-285.

Umbriaco, D., Watkins, K.C., Descarries, L., Cozzari, C., and Hartman, B.K. 1994. Ultrastructural and morphometric features of the acetylcholine innervation in adult rat parietal cortex: An electron microscopic study in serial sections. J. Comp. Neurol. 348: 351-373.

Vidal, C. and Changeux, J.-P. 1989. Pharmacological profile of nicotinic acetylcholine receptors in the rat prefrontal cortex: An electrophysiological study in a slice preparation. Neuroscience 29: 261-270.

. 1993. Nicotinic and muscarinic modulations of excitatory synaptic transmission in the rat prefrontal cortex in vitro. Neuroscience 56: 23-32.

Warburton, D.M. 1992. Nicotine as a cognitive enhancer. Prog. Neuropsychopharmacol. Biol. Psychiatry 16: 181-191.

Weinberger, N.M. and Bakin, J.S. 1998. Learning-induced physiological memory in adult primary auditory cortex: Receptive fields plasticity, model, and mechanisms. Audiol. Neurootol. 3: 145-167.

Wonnacott, S. 1997. Presynaptic nicotinic ACh receptors. Trends Neurosci. 20: 92-98.

Woodson, P.P., Baettig, K., Etkin, M.W., Kallman, W.M., Harry, G.J., Kallman, M.J., and Rosecrans, J.A. 1982. Effects of nicotine on the visual evoked response. Pharmacol. Biochem. Behav. 17: 915-920.

Xiang, Z., Huguenard, J.R., and Prince, D.A. 1998. Cholinergic switching within neocortical inhibitory networks. Nature 281: 985-988.

Yamada, S., Kagawa, Y., Isogai, M., Takayanagi, N., and Hayashi, E. 1986. Ontogenesis of nicotinic acetylcholine receptors and presynaptic cholinergic neurons in mammalian brain. Life Sci. 38: $637-644$.

Yuste, R. and Sur, M. 1999. Development and plasticity of the cerebral cortex: From molecules to maps. J. Neurobiol. 41: 1-6.

Zhang, Z., Vijayaraghavan, S., and Berg, D.K. 1994. Neuronal acetylcholine receptors that bind $\alpha$-bungarotoxin with high affinity function as ligand-gated ion channels. Neuron 12: 167-177. 


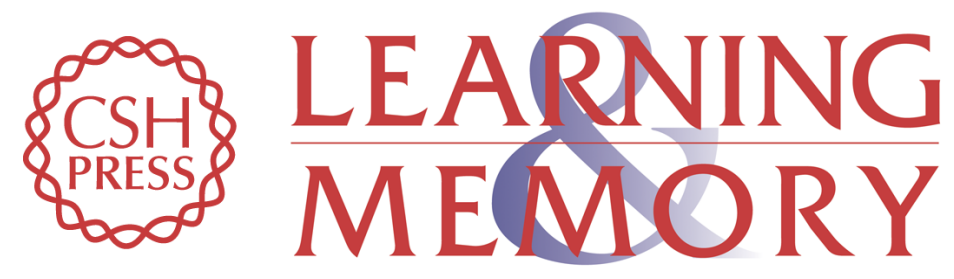

\section{Nicotinic Acetylcholine Receptors in Sensory Cortex}

Raju Metherate

Learn. Mem. 2004, 11:

Access the most recent version at doi:10.1101/lm.69904

References This article cites 138 articles, 18 of which can be accessed free at: http://learnmem.cshlp.org/content/11/1/50.full.html\#ref-list-1

License

Email Alerting Receive free email alerts when new articles cite this article - sign up in the box at the Service top right corner of the article or click here. 